ONLINE MUTATION REPORT

\title{
Spectrum of atrial septal defects associated with mutations of NKX2.5 and GATA4 transcription factors
}

\author{
A Sarkozy, E Conti, C Neri, R D’Agostino, M C Digilio, G Esposito, A Toscano, B Marino, A Pizzuti, \\ B Dallapiccola
}

J Med Genet 2005;42:el6 (http://www.jmedgenet.com/cgi/content/full/42/2/el6). doi: 10.1136/jmg.2004.026740

A trial septal defect (ASD) is a common cardiovascular malformation, affecting over 1 in 1000 live births, accounting for $10 \%$ of congenital heart defects (CHD). ${ }^{1}$ ASD refers to a communication between the right and left atria, anatomically classified into the deficient atrial septum structure. ASD ostium secundum (ASDos) is the prevalent defect, representing $85 \%$ of all ASDs. ${ }^{2}$ ASD may be isolated or associated with other CHDs, such as pulmonary valve stenosis (PVS), ventricular septal defect (VSD), or conduction defects. In addition, persistent left to right blood shunt may result in atrial and ventricular dysfunctions and atrial arrhythmias, in the absence of surgical or catheter based repair.

The atrial septum is one of the cardiac structures most sensitive to environmental or genetic factors. Several lines of evidence have highlighted a role for different proteins and transcription factors in the septogenesis process; ${ }^{3}$ however, only two genes, encoding for the transcription factors NKX2.5 and GATA4, have been implicated so far in nonsyndromic ASDs. ${ }^{45}$ Clinical and molecular analyses have shown that mutations in these two genes are responsible for ASDs in association with distinct cardiac features. ${ }^{4-15}$ Mutations in NKX2.5, a member of the NK-2 class of homeobox genes, have been described in autosomal dominant ASDos with progressive atrioventricular (AV) block, and in $1-4 \%$ of sporadic ASD patients. ${ }^{4-12}$ Most of these mutations occur within the homeodomain, a critical protein domain that interacts specifically with DNA, and are associated with conduction anomalies. Low penetrance NKX2.5 gene mutations, mainly outside the homeodomain, have been found in 5\% of patients with tetralogy of Fallot, and in a number of individuals with other CHDs and normal conduction. ${ }^{4}{ }^{9-13}$ Recently, heterozygous mutations in the GATA4 zinc finger transcription factor gene have been identified in three families with autosomal dominant ASDos and normal conduction. ${ }^{514}$ Individuals with GATA4 mutations may also show concurrent CHDs, in particular PVS.

In this study, we screened the NKX2.5 and GATA4 genes in a cohort of Italian families and sporadic patients affected by non-syndromic ASDs, in order to assess the prevalence of these mutations and appraise any genotype-phenotype correlations.

\section{METHODS}

\section{Subjects}

Patients were recruited at the Pediatric Cardiology Unit of the Bambino Gesù Hospital and Policlinico Umberto I Hospital in Rome, Italy. Sporadic patients were enrolled from July 2003 to April 2004, while families were selected from a cohort of patients recruited retrospectively for genetic studies on CHDs from 1995 to 2004. Clinical assessment included complete physical evaluation of dysmorphisms and malformations,

\section{Key points}

- Heterozygous mutations in the NKX2.5 and GATA4 genes have been detected in patients with atrial septal defect (ASD) and other congenital heart defects.

- In order to assess the mutations prevalence and appraise any genotype-phenotype correlations, we screened NKX2.5 and GATA4 in a cohort of patients with isolated ASD or ASD associated with concurrent heart defects.

- NKX2.5 and GATA4 coding regions were screened by direct sequencing in 16 familial and 13 sporadic ASD patients.

- We identified one previously reported GATA4 and three novel NKX2.5 mutations. The NKX2.5 mutations (one missense and two frameshifts) were detected in two families and one sporadic patient. ASD was detected in all affected individuals, and adults also showed conduction anomalies. In addition, multiple muscular ventricular septal defects and non-compaction of the left ventricular myocardium were detected in one kindred. The Gly296Ser GATA4 mutation was found in two families segregating ASD and pulmonary valve stenosis (PVS) with normal conduction.

- These results confirm that NKX2.5 and GATA4 mutations are major causes of different patterns of ASDs, mostly in familial cases. While associated conduction defects are strongly suggestive for NKX2.5 mutations, PVS with normal conduction should require GATA4 gene screening first.

anthropometric measurements, renal ultrasonography, and radiological studies. Cardiac evaluation included preoperative chest $x$ ray film, 12 lead electrocardiogram, and two dimensional transthoracic echocardiography with colour flow Doppler. All patients had a classic form of ASDos, with a defect diameter of $>5 \mathrm{~mm}$. Family history was assessed in all cases. The patients' parents and available family members were investigated for cardiac and extracardiac anomalies. After written informed consent, blood samples were obtained from all available affected individuals and unaffected parents, when possible. Karyotype analysis was performed in all patients. Criteria for patient exclusion were: major CHDs such as single ventricle and conotruncal anomalies, distinct syndromic associations, and identified chromosomal anomaly including 22q11 deletion. Sporadic and familial index patients were included in the mutation screening. Following mutation identification, molecular analysis was also performed in affected and unaffected relatives. 


\section{Molecular analysis}

The NKX2.5 and GATA4 gene coding regions and exon-intron boundaries, including about $50 \mathrm{bp}$ upstream and downstream from the exons, were amplified from genomic DNA by PCR using standard techniques. The PCR products were sequenced by the Big Dye Terminator ABI Prism sequencing kit (Applied Biosystems, Foster City, CA, USA), and run on an ABI Prism 3100 Genetic Analyzer automated sequencer (Applied Biosystems).

\section{RESULTS}

The ASD study group included 16 families (Fam.01-16) with multiple affected members and 13 unrelated sporadic individuals (Sp.01-13). Familial index patients were six males and 10 females, with an age ranging between 0.9 and 17 years. In nine families, ASDos segregated as an isolated anomaly. AV conduction defects, VSD, PVS, left ventricular myocardium noncompaction (LVMN), atrioventricular canal defect (AVCD), anomalous pulmonary venous return (APVN), and mitral valve prolapse (MVP) were observed as concurrent CHDs in the remaining families. There were six male and seven female sporadic patients, whose ages ranged between 3 and 35 years. Four of these patients presented concurrent cardiac defects: AV block in Sp.01, VSD plus PVS in Sp.04, PVS in Sp.05, and supraventricular tachycardia in Sp.06. NKX2.5 or GATA4 sequence variations were detected in five of the 29 index patients (17\%) (table 1). Detailed pedigrees of familial and sporadic patients with mutation are shown in fig 1.

\section{NKX2.5 mutations}

None of the detected NKX2.5 mutations has been previously reported. Two DNA sequence variations involved amino acid changes in the homeodomain and one involved a change in the $\mathrm{C}$ terminus of the protein. Two mutations are predicted to cause premature terminations of translation. The first, a heterozygous $1 \mathrm{bp}$ insertion in the homeodomain (498499insC), results in a frameshift and a premature stop codon at amino acid 250, with a 75 amino acid deletion at the C terminal. The second is a heterozygous 2 bp deletion (605606delTG), also causing an identical premature termination of translation. The heterozygous $554 \mathrm{G} \rightarrow \mathrm{T}$ mutation results in a Trp185Leu codon change affecting the homeodomain. We regard these DNA sequence variations as pathogenic mutations, because of their co-segregation with the disease in the familial cases, the truncating nature of the mutation or the involvement of a highly conserved amino acid (Trp185), and the negative results from 100 normal chromosomes from a random control population.

The 605-606delTG mutation was found in three members of family 1. The proband (IV:1), at the age of 6 years, manifested ASDos with second degree AV block. Her mother (III:3) was affected by ASDos, complete AV block, and VSD. Individual II:3, at the age of 65 years, showed ASDos with

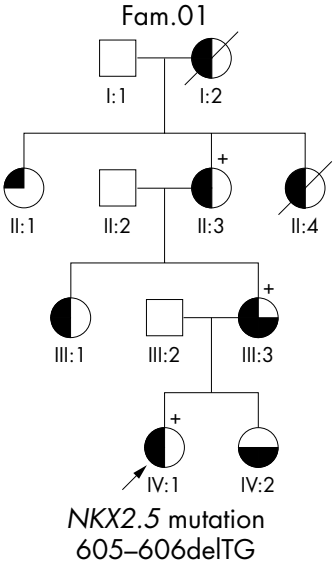

B

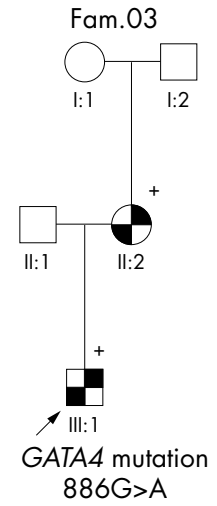

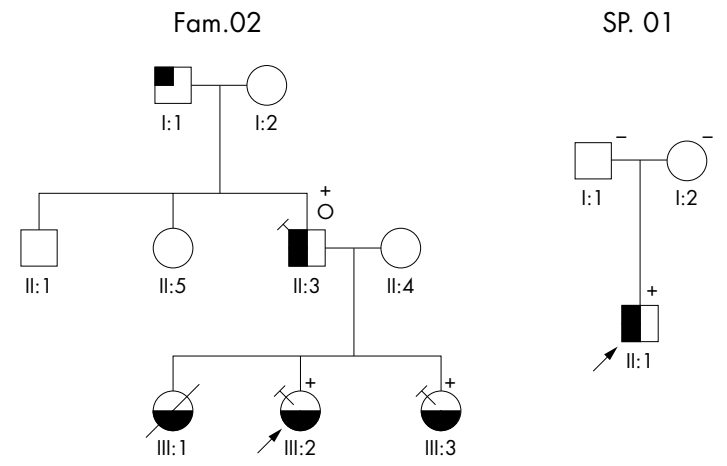

NKX2.5 mutation $554 \mathrm{G}>\mathrm{T}$

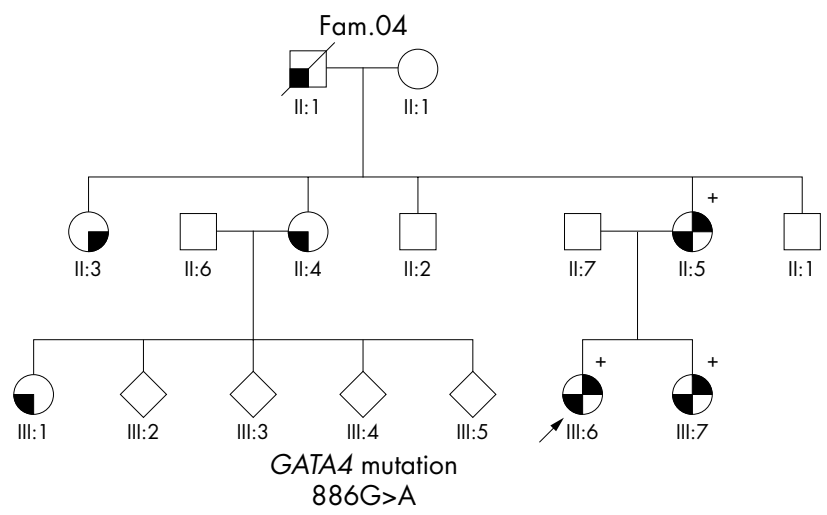

Figure 1 Pedigrees of patients with NKX2.5 (A) or GATA4 (B) mutations. Different symbols indicate distinct cardiac defects; +/ - symbol represents presence/absence of mutation. Arrows indicate index patients. The mutation found in each family is specified under the pedigree.
Atrial septal defect ostium secundum

Pulmonary valve stenosis

Atrioventricular conduction anomalies
Ventricular septal defect

- Mitral valve prolapse

Left ventricular myocardium noncompaction 
Table 1 Clinical and molecular characteristics of familial and sporadic patients

\begin{tabular}{|c|c|c|c|c|c|c|c|}
\hline \multirow[b]{2}{*}{ Mutation } & \multirow[b]{2}{*}{$\begin{array}{l}\text { Familial } \\
\text { patients }\end{array}$} & \multirow[b]{2}{*}{$\begin{array}{l}\text { Sporadic } \\
\text { patients }\end{array}$} & \multicolumn{5}{|c|}{ Cardiac defects } \\
\hline & & & ASDos & VSD & PVS & $\begin{array}{l}\text { AV } \\
\text { block }\end{array}$ & Other \\
\hline NKX2.5 & 2 & 1 & 3 & $2^{*}$ & 0 & 3 & 1 LVMN; 1 MVP \\
\hline GATA4 & 2 & 0 & 2 & 1 & 2 & 0 & \\
\hline Negative & 12 & 12 & 24 & 2 & 3 & 0 & 1 AVCD; 1 APVR, 1 SVT \\
\hline Total & 16 & 13 & 29 & 5 & 5 & 3 & 5 \\
\hline
\end{tabular}

*One familial case with multiple muscular ventricular septal defects. ASDos, atrial septal defect ostium secundum VSD, ventricular septal defect; PVS, pulmonary valve stenosis; AV, atrioventricular; LVMN, left ventricular myocardial noncompaction; MVP, mitral valve prolapse; AVCD, atrioventricular canal defect; APVR, anomalous pulmonary venous return; SVT, supraventricular tachycardia.

ECG evidences of AV block. Individuals II:1, III:1, and IV:2 were not available for molecular testing. While subject II: 1 had a history of isolated rhythm anomalies, individuals III: 1 and IV:2 were affected by ASDos, in association with rhythm disturbances in III: 1 and VSD in IV:2, respectively (fig 1A).

The $554 \mathrm{G} \rightarrow \mathrm{T}$ mutation was identified in three affected members of family 2 . The proband (III:2), a 9 month old girl, and her younger sister (III:3) had ASDos, associated with multiple muscular VSDs ("Swiss cheese" VSD). Their father (II:3), who was affected by ASDos with complete AV block and MVP, had undergone a surgical repair and a pacemaker implantation. Both affected father and daughters showed echocardiographic findings of LVMN. The paternal grandfather (I:1), who was not genotyped, had a history of rhythm disturbances and pacemaker implantation. Individual III:1 was diagnosed in infancy with ASDos and multiple muscular VSDs, and died of severe heart failure at 8 months of age. Blood samples were not available from individuals II: 1 and II:5, who were reported as clinically normal (fig lA).

The 498-499insC frameshift de novo mutation was detected in patient Sp.01 (individual II:1), who was diagnosed with ASDos and a second degree AV block in early infancy. The ASD was corrected at the age of 6 years (fig 1A).

\section{GATA4 mutations}

The $886 \mathrm{G} \rightarrow \mathrm{A}$ (Gly296Ser) GATA4 mutation, previously reported by Garg et al, was identified in two kindreds. ${ }^{5}$ This mutation segregated in two members of family 3 (II:2 and III:1), both affected by ASDos and PVS, with a right ventricle to pulmonary artery gradient $>40 \mathrm{mmHg}$, which required a surgical repair. In individual III:1, hypospadia was diagnosed in infancy. Parents of individual I: 1 were not blood sampled, but they were reported as clinically normal (fig 1B).

The $886 \mathrm{G} \rightarrow \mathrm{A}$ mutation was also identified in individuals II:5, III:6, and III:7 of family 4, all of whom were affected by ASDos and PVS with a right ventricle to pulmonary artery gradient of $50 \mathrm{mmHg}$, which was surgically corrected at the age of 25 years in II:5 and at the age of 1 year in III:7. Blood samples were not available from other affected members (II:3, II:4, and III:1), who had a history of a ASD or VSD (details unavailable). ASDos was echographically diagnosed in the deceased family member I:1 (fig 1B).

\section{DISCUSSION}

Functional haploinsufficiency of NKX2.5 and GATA4 genes represents an important cause of non syndromic ASDs. In the present study we identified one recurrent GATA4 and three novel NKX2.5 mutations, associated with different types of CHDs, including ASDs.

The most consistent CHDs associated with the NKX2.5 mutations reported here were ASDos, AV block, and VSD. Previous studies have shown that missense mutations within the gene homeodomain (in particular those located in the third helix, such as the Trp185Leu change identified in family 2 ) reduce DNA binding and transcriptional activation. ${ }^{16}$ These mutations result in fully penetrant ASD and AV block. ${ }^{46}$ In two subjects, Trp185Leu was also associated with multiple muscular VSDs, a feature previously reported only in a family segregating the Tyr259ter mutation. ${ }^{6}$ LVMN, diagnosed in all subjects with Trpl85Leu mutation, has been previously reported in association with $N K X 2.5$ haploinsufficiency only once, in a patient with $5 \mathrm{q}$ deletion. ${ }^{17}$ The cardiac features shown by the affected members of family 2 reveal a pathogenetic link between multiple muscular VSD and LVMN. Previous studies have shown that mice with a ventricular restricted knockout of the $N k \times 2.5$ gene exhibit echocardiographic and histological evidence of LVMN, and analogous myocardial findings have been also reported in the hypomorphic Gata4 murine model and in the Tbx5 deficient mice. ${ }^{151819}$ It is notable that haploinsufficiency of the TBX5 transcription factor in humans is responsible for septal and conduction defects in Holt-Oram syndrome. ${ }^{20}{ }^{21}$ This clinical and molecular evidence supports the functional connection between NKX2.5, GATA4, and TBX5 in cardiogenesis and cardiac diseases. ${ }^{22} 23$

Mutations at the $\mathrm{C}$ terminal cause protein truncation after the homeodomain, and result in hypomorphic mutant proteins, with a normal monomeric DNA binding ability, and reduced transcriptional activity. ${ }^{16}$ Individuals with truncating mutations after the homeodomain manifest CHDs overlapping those found in individuals with mutations inside the homeodomain. ${ }^{467}$ In fact, the 605-606delTG and 498-499insC mutations resulted in ASD and AV block, associated with VSD in two members of family 2 . Interestingly, these mutations, as well as the 701702insTCCCT mutation and the two nonsense $886 \mathrm{C} \rightarrow \mathrm{A}$ and $90 \mathrm{lC} \rightarrow \mathrm{A}$ mutations, ${ }^{6812}$ predict analogous truncated proteins (missing $\sim 250$ amino acids), arguing for an association between these mutations and ASD with AV block. It is noteworthy that in the present cohort a number of young individuals with NKX2.5 mutations had normal cardiac conduction. Heart restricted knockout $N k \times 2.5$ mice manifest defects in AV nodal and working myocyte cell lineages, chamber morphogenesis, maturation, and specification, with gradual nodal degeneration and cell dropout. ${ }^{19}$ Progressive AV nodal degeneration has also been documented in individuals with $N K X 2.5$ mutations, supporting the role of NKX2.5 in the maintenance and maturation of human AV nodal myocytes. ${ }^{19}$ Accordingly, AV block was invariably present in our series of adults with NKX2.5 mutations, supporting a role of this protein in preserving integrity of the conduction system.

Affected individuals, segregating the Gly296Ser GATA4 mutation (families 3 and 4), manifested ASDos associated with PVS, in the absence of conduction defects. This observation corroborates previous evidences for an association between GATA4 mutations and ASD with semilunar 
valve malformations. ${ }^{5}{ }^{14}{ }^{15}$ In particular, the Gly296Ser mutation, previously reported in one kindred, resulted in full penetrant autosomal dominant ASD and PVS with normal conduction. ${ }^{5}$ It has been demonstrated that GATA4, which is expressed throughout the developing heart, is essential for heart formation, through interaction with other transcription factors including NKX2.5.22 2425 The Gly296Ser mutation affects a highly conserved amino acid localised between the $\mathrm{C}$ terminal zinc finger and the nuclear localising signal. This, in turn, not only changes the DNA binding affinity and the transactivation of downstream targets, but also disrupts the interaction between GATA4 and TBX5. ${ }^{5}$ While TBX5 mutations lead to syndromic ASD with conduction defect, ${ }^{20} 21$ GATA4 mutations also cause malformations of the pulmonary outflow tract (including PVS) and extracardiac abnormalities, supporting its role in the morphogenesis of different structures. The same conclusions have also been drawn for the GATA4 gene haploinsufficiency. Distal $8 p$ deletions in humans are characterised by a wide spectrum of CHDs, microcephaly, other physical anomalies, and mental retardation. ${ }^{26}$ The contribution of GATA4 to the $8 \mathrm{p}$ cardiac phenotype has been postulated, ${ }^{27}$ although other evidence has mapped GATA4 outside the critical region for this condition. ${ }^{28}$ Heterozygous GATA4 mutations cause distinct cardiac defects, such as ASD, PVS, AVCD, and dextrocardia, which are also features of $8 \mathrm{p}$ syndrome. ${ }^{51426}$ Interestingly, one of the patients with Gly296Ser mutation (individual II:1, family 3) also had hypospadia, a defect found in six of seven previously described 8p patients. ${ }^{26}$ However, no patient with a GATA4 mutation manifested additional extracardiac malformations or mental retardation, arguing for a role of GATA4 haploinsufficiency in CHDs and, possibly, genital anomalies, in agreement with its expression pattern. ${ }^{29}$

While NKX2.5 and GATA4 mutations may both result in ASDos and VSD, involvement of each of these two genes causes some consistent difference in the pattern of cardiac defects, notably in the conduction system and the semilunar valves. Conduction anomalies do not associate with GATA4 mutations, while NKX2.5 haploinsufficiency may also affect the semilunar valves but is generally found in pulmonary valve atresia and tetralogy of Fallot..$^{13}$ Intrafamilial variability appears to be age related. In fact, conduction defects, although not detected in infancy, can manifest with increasing age, while spontaneous healing of small VSDs results in an intact septum during adulthood.

We detected GATA4 mutations only in familial cases, while NKX2.5 mutations were also identified in sporadic individuals. Analysis of families with mutations supports full penetrance, although the unavailability of some unaffected family members in kindreds with mutations weakens this conclusion.

A prevalence of about $1-4 \%$ of $N K X 2.5$ mutations in sporadic patients with ASDs has been estimated from three previous studies. ${ }^{811}{ }^{12}$ No consistent figure is available on the prevalence of mutations in the familial cases, although a single study has reported one unique mutated family of 13 analysed kindreds (8\%). ${ }^{11}$ The prevalence of NKX2.5 mutations in the personal series of sporadic cases $(1 / 13 ; 8 \%)$, even if not significant because of the low patient numbers, is consistent with the reported low mutation rate in sporadic ASDs. In contrast, although our familial cohort is also not large, the figure of $2 / 16$ mutations ( $12.5 \%$ ) in our pedigrees suggests that the $N K X 2.5$ mutations could be a major cause of familial ASDs. Notably, we found NKX2.5 mutations in all families and sporadic patients with AV block. We detected GATA4 mutations in two of 16 families (12.5\%), including two of five individuals with semilunar valves malformations. Thus, GATA4 seems to be an important gene involved in this type of ASD. Genetic heterogeneity of ASDs was proved by an inability to detect mutations in $83 \%$ of our patients. However, the contribution of genes other than NKX2.5 and GATA4 in ASD pathogenesis appears likely, particularly in the absence of conduction defects.

In conclusion, the present results corroborate functional links between the transcription factors NKX2.5, GATA4, and TBX5 in cardiac morphogenesis, and confirm that NKX2.5 and GATA4 gene mutations cause distinct patterns of ASDs. The frequency of $N K X 2.5$ mutations in familial ASD with AV block recommends molecular testing in this subtype of defects, while GATA4 screening is indicated in familial ASD associated with PVS and normal cardiac conduction. Therefore, molecular diagnosis should assist with the clinical management of ASD and improve genetic counselling in these families.

\section{ACKNOWLEDGEMENTS}

This study was supported in part by grants from the Italian Ministry of Health (Ricerca Finalizzata 2003 and Ricerca Corrente 2004).

\section{Authors' affiliations}

A Sarkozy, E Conti, C Neri, G Esposito, A Pizzuti, B Dallapiccola, CSS Hospital, IRCCS, San Giovanni Rotondo, Italy, and CSS- Mendel Institute, Rome

A Sarkozy, C Neri, G Esposito, A Pizzuti, B Dallapiccola, Department of Experimental Medicine and Pathology, University "La Sapienza", Rome R D'Agostino, B Marino, Section of Pediatric Cardiology, Department of Pediatrics, University "La Sapienza", Rome

M C Digilio, Division of Medical Genetics, Bambino Gesù Hospital, IRCCS, Rome

A Toscano, Division of Pediatric Cardiology, Bambino Gesù Hospital, IRCCS, Rome

Competing interests: none declared

Correspondence to: Professor B Dallapiccola, CSS-Mendel Institute, Viale Regina Margherita 261, 00198 Rome, Italy;

dallapiccola@css-mendel.it

Received 25 August 2004

Revised 26 October 2004

Accepted 2 November 2004

\section{REFERENCES}

1 Hoffmann JI, Kaplan S. The incidence of congenital heart defects. Am J Coll Cardiol 2002;39:1890-900.

2 Jacobs JP, Quintessenza JA, Burke Rp, Mavroudis C. Congenital Heart Surgery Nomenclature and Database Project : atrial septal defect. Ann Thorac Surg 2000;69:S18-24.

3 Vaughan CJ, Basson CT. Molecular determinants of atrial and ventricular septal defects and patent ductus arteriosus. Am J Med Genet (Semin Med Genet) 2001;97:304-9

4 Schott JJ, Benson DW, Basson CT, Pease W, Silberbach GM, Moak JP Maron BJ, Seidman CE, Seidman JG. Congenital heart disease caused by mutations in the transcription factor NKX2.5. Science 1998;281:108-11.

5 Garg V, Kathiriya IS, Barnes R, Schluterman MK, King IN, Butler CA Rothrock CR, Eapen RS, Hirayama-Yamada K, Joo K, Matsuoka R, Cohen JC, Srivastava D. GATA4 mutations cause human congenital heart defects and reveal an interaction with TBX5. Nature 2003;424:443-7.

6 Benson DW, Silberbach GM, Kavanaugh-McHugh A, Cottrill C, Zhang Y, Riggs S, Smalls O, Johnson MC, Watson MS, Seidman JG, Seidman CE, Plowden J, Kugler JD. Mutations in the cardiac transcription factor NKX2.5 affect diverse cardiac developmental pathways. J Clin Invest 1999; 104:1567-73.

7 Hosoda T, Komuro I, Shiojima I, Hiroi Y, Harada M, Murakawa Y, Hirata Y, Yazaki Y. Familial atrial septal defect and Atrioventricular conduction disturbance associated with a point mutation in the cardiac homeobox gene CSX/NKX2.5 in a Japanese patient. Jpn Circ J 1999;63:425-6.

8 Ikeda Y, Hiroi Y, Hosoda T, Utsunomiya T, Matsuo S, Ito T, Inove J, Sumiyoshi T, Takano H, Nagai R, Komuro I. Novel point mutation in the cardiac transcription factor CSX/NKX2.5 associated with congenital heart disease. Circ J 2002;66:561-3.

9 Watanabe Y, Benson DW, Yano S, Akagi T, Yoshino M, Murray JC. Two novel frameshift mutations in NKX2.5 result in novel features including visceral inversus and sinus venosus type ASD. J Med Genet 2002;39:807-11.

10 Gutierrez-Roelens I, Sluysmans T, Gewillig M, Devriendt K, Vikkula M. Progressive AV-block and anomalous venous return among cardiac anomalies associated with two novel missense mutations in the CSX/NKX2-5 gene. Hum Mutat 2002;20:75-6. 
11 Elliott DA, Kirk EP, Yeoh T, Chandar S, McKenzie F, Taylor P, Grossfeld P, Fatkin D, Jones $O$, Hayes $P$, Feneley M, Harvey RP. Cardiac homeobox gene NKX2-5 mutations and congenital heart disease. J Am Coll Cardiol 2003:41:2072-6

12 McElhinney DB, Geiger E, Blinder J, Benson DW, Goldmuntz E. NKX2.5 mutations in patients with congenital heart disease. J Am Coll Cardiol 2003;42:1650-5

13 Goldmuntz E, Geiger E, Benson DW. NKX2.5 mutations in patients with tetralogy of Fallot. Circulation 2001; 104:2565-8.

14 Okubo A, Miyoshi O, Baba K, Takagi M, Tsukamoto K, Kinoshita A Yoshiura K, Kishino T, Ohta T, Niikawa N, Matsumoto N. A novel GATA4 mutation completely segregated with atrial septal defect in a large Japanese family. J Med Genet 2004;41:e97.

15 Hatcher CJ, Diman NYS-G, McDermott DA, Basson CT. Trascription factor cascades in congenital heart malformation. Trends Mol Med 2003:9.512-5.

16 Kasahara H, Lee B, Schott J, Benson DW, Seidman JG, Seidman CE, Izumo S. Loss of function and inhibitory effects of human CSX/NKX2.5 homeoprotein mutations associated with congenital heart disease. J Clin Invest 2000;106:299-308

17 Pauli RM, Scheib-Wixted S, Cripe L, Izumo S, Sekhon GS. Ventricular noncompaction and distal chromosome $5 q$ deletion. Am J Med Genet 1999;85:419-23.

18 Bruneau BG, Nemer G, Schmitt JP, Charron F, Robitaille L, Caron S, Conner DA, Gessler M, Nemer M, Seidman CE, Seidman JG. A murine mode of Holt-Oram syndrome defines roles of the T-box transcritpion factor Tbx5 in cardiogenesis and disease. Cell 2001;106:709-21.

19 Pashmforoush M, Lu JT, Chen H, Amand TS, Kondo R, Pradervand S, Evans SM, Clark B, Feramisco JR, Giles W, Ho SY, Benson DW, Silberbach M Shou W, Chien KR. Nkx2-5 pathways and congenital heart disease; loss of ventricular myocyte lineage specification leads to progressive cardiomyopathy and complete heart block. Cell 2004;1 17:373-86.

20 Basson CT, Bachinsky DR, Lin RC, Levi T, Elkins JA, Soults J, Grayzel D, Kroumpouzou E, Traill TA, Leblanc-Straceski J, Renault B, Kucherlapati R,
Seidman JG, Seidman CE. Mutations in human TBX5 (corrected) cause limb and cardiac malformation in Holt-Oram syndrome. Nat Genet 1997; 15:30-5

21 Li QY, Newbury-Ecob RA, Terrett JA, Wilson DI, Curtis AR, Yi CH, Gebuhr T, Bullen PJ, Robson SC, Strachan T, Bonnet D, Lyonnet S, Young ID, Raeburn JA, Buckler AJ, Law DJ, Brook JD. Holt-Oram syndrome is caused by mutations in TBX5, a member of the Brachyury (T) gene family. Nat Genet 1997;15:21-9.

22 Durocher D, Charron F, Warren R, Schwartz RJ, Nemer M. The cardiac transcription factors $\mathrm{Nkx2-5}$ and GATA-4 are mutual cofactors. EMBO 1997; 16:5687-96.

23 Hiroi Y, Kudoh S, Monzen K, Ikeda Y, Yazaki Y, Nagai R, Komuro I. Tbx5 associates with $\mathrm{Nkx2-5}$ and synergistically promotes cardiomyocyte differentiation. Nat Genet 2001;28:276-80.

24 Molkentin JD, Lin Q, Duncan SA, Olson EN. Requirement of the transcription factor GATA4 for heart tube formation and ventral morphogenesis. Genes Dev 1997; 11:1061-72.

25 Kuo CT, Morrisey EE, Anandappa R, Sigrist K, Lu MM, Parmacek MS, Soudais $C$, Leiden JM. GATA4 transcription factor is required for ventral morphogenesis and heart tube formation. Genes Dev 1997;11:1048-60.

26 Digilio MC, Marino B, Guccione P, Giannotti A, Mingarelli R, Dallapiccola B. Deletion 8p syndrome. Am J Med Genet 1998;75:534-6.

27 Pehlivan T, Pober BR, Brueckner M, Garrett S, Slaugh R, Van Rheeden R, Wilson DB, Watson MS, Hing AV. GATA4 haploinsufficiency in patients with interstitial deletion of chromosome region 8p23.1 and congenital heart disease. Am J Med Genet 1999;83:201-6.

28 Giglio S, Graw SL, Gimelli G, Pirola B, Varone P, Voullaire L, Lerzo F, Rossi E, Dellavecchia C, Bonaglia MC, Digilio MC, Giannotti A, Marino B, Carrozzo R, Korenberg JR, Danesino C, Sujansky E, Dallapiccola B, Zuffardi O. Deletion of a 5 -cM region at chromosome 8 p23 is associated with a spectrum of congenital heart defects. Circulation 2000;102:432-7.

29 Molkentin JD. The zinc finger-containing transcription factors GATA-4, -5, and -6. Ubiquitously expressed regulators of tissue-specific gene expression. J Biol Chem 2000;275:38949-52. 